Check for updates

Cite this: RSC Adv., 2018, 8, 4112

Received 23rd November 2017

Accepted 4th January 2018

DOI: $10.1039 / c 7 r a 12705 g$

rsc.li/rsc-advances

\section{Au-doped $\mathrm{Li}_{1.2} \mathrm{Ni}_{0.7} \mathrm{Co}_{0.1} \mathrm{Mn}_{0.2} \mathrm{O}_{2}$ electrospun nanofibers: synthesis and enhanced capacity retention performance for lithium-ion batteries}

\author{
Bin Yue, Xinlu Wang, (D) Jinxian Wang, (D) Jing Yao, Xinru Zhao, Hongbo Zhang, \\ Wensheng Yu, Guixia Liu (D) and Xiangting Dong (D)
}

\begin{abstract}
The Au-doped $\mathrm{Li}_{1.2} \mathrm{Ni}_{0.7} \mathrm{CO}_{0.1} \mathrm{Mn}_{0.2} \mathrm{O}_{2}(\mathrm{Au}=0 \%, 1 \%, 2 \%, 3 \%, 4 \%)$ nanofibers are successfully prepared by electrospinning technology. The impact of Au doping on the structure, morphology and electrochemical properties of samples is studied in detail. The X-ray diffraction patterns demonstrate that appropriate Audoping does not significantly change the structure of $\mathrm{Li}_{1.2} \mathrm{Ni}_{0.7} \mathrm{Co}_{0.1} \mathrm{Mn}_{0.2} \mathrm{O}_{2}$. Scanning electron microscope images revealed the electrospun nanofibers have uniform particle size in the range of 300$400 \mathrm{~nm}$. The optimum doping amount of $\mathrm{Au}$ is $2 \%$ in $\mathrm{Li}_{1.2} \mathrm{Ni}_{0.7} \mathrm{Co}_{0.1} \mathrm{Mn}_{0.2} \mathrm{O}_{2}$ to obtain high discharge capacity and excellent capacity retention. Electrochemical impedance spectroscopy test results elucidated that the LNCMA-2\% cell has excellent $\mathrm{Li}^{+}$electrical conductivity and lower charge transfer resistance. The results show that stable structure with good particle contact of the Au-doped cathode materials can enhance electrochemical properties, which can be interpreted as an important inhibition of phase transitions and increased charge transfer impedance during cycling.
\end{abstract}

\section{Introduction}

Lithium-ion batteries (LIBs) are extensively utilized as electrochemical power sources for industrial applications, particularly in the field of electric vehicles (EVs) and hybrid electric vehicles (HEVs) owing to their significant electrochemical behavior. Research and development for high capacity, low price and safe cathode materials is critical for LIBs to meet the demands of potential applications. Due to the imperfections of $\mathrm{LiCoO}_{2}$, such as high cost and toxicity of cobalt, $\mathrm{LiMnO}_{2}$ and $\mathrm{LiNiO}_{2}$ have drawn increasing attention as natural substitutes. However, they are hard to synthesize due to the fact that their structure is precarious during the annealing process. In addition, phase transition easily takes place during chargedischarge process, resulting in poor cyclic retention. ${ }^{1}$ Therefore, the layered oxide $\mathrm{LiMO}_{2}(\mathrm{M}=\mathrm{Mn}, \mathrm{Ni}, \mathrm{Co})$, which has been explored in detail, is considered as one of the most promising substitutions of cathode materials ${ }^{2-12}$ owing to its adequate resources, lower toxicity, and low cost. ${ }^{13,14}$ However, the poor capacity retention at a high operating voltage of $>4.3 \mathrm{~V}$ or high current density restricts its application; also, the mechanism of capacity fading has not been systematically and comprehensively understood. ${ }^{15}$ Accordingly, further research to increase both $\mathrm{Ni}$ content and the cutoff voltage to more than $4.5 \mathrm{~V}$ is being carried out to improve the energy density of cathodes. ${ }^{16-19}$

Key Laboratory of Applied Chemistry and Nanotechnology at Universities of Jilin Province, Changchun University of Science and Technology, Changchun 130022, China.E-mail:wjx87@sina.com
Ni-rich $\mathrm{LiNi}_{x} \mathrm{Co}_{y} \mathrm{Mn}_{1-x-y} \mathrm{O}_{2}$ electrodes display excellent discharge capacity. The discharge capacity increases on increasing the Ni content, but the detrimental thermal instability was attributed to the higher $\mathrm{Ni}^{2+}$ amount in Ni-rich materials. The cathode could be partially transformed into an electrochemically inactive NiO-like phase or spinel structure because of volumetric changes ${ }^{20,21}$ ascribed to the migration of the Ni cations from the transition metal (TM) layers to the lithium layers. In addition, the increased formation of $\mathrm{NiO}$ phase leads to capacity fading. The undesired changes of volume could be responsible for the pulverization of the active materials, which were detached from the secondary particles, leading to the increase in cell impedance. ${ }^{22,23}$ Moreover, there are several intrinsic problems with the Ni-rich $\mathrm{LiNi}_{x} \mathrm{Co}_{y^{-}}$ $\mathrm{Mn}_{1-x-y} \mathrm{O}_{2}$ that need to be solved. The electrodes always suffer from low discharge capacity and inferior rate performance due to low electric and ionic conductivity and poor capacity retention arising from the dissolution of Mn during long-term cycling. ${ }^{24}$ Consequently, their application in practical LIBs has been impeded by these defects. To compensate for the above problems of $\mathrm{LiNi}_{x} \mathrm{Co}_{y} \mathrm{Mn}_{1-x-y} \mathrm{O}_{2}$, numerous studies have been performed to optimize similar materials using new synthesis methods, coatings and substitutes for $\mathrm{Ni}, \mathrm{Mn}$, or Co, oxides, phosphates, carbon and fluorides have been used for surface modification and proved to be an effective way to hinder dissolution of transition metals and undesired reactions between cathode and electrolyte. ${ }^{25-31}$ The coated layer could suppress the undesired surface side reactions and enhance the cyclic stability of layered oxides. However, the thickness of the 
coating layer must be carefully controlled to avoid hindering the active Li diffusion responsible for heavy coating layers. Moreover, the electrochemical properties can be enhanced by doping ions, ${ }^{32-34}$ which can prevent structure transformations and enhance the diffusivity of electrons and lithium ions in the cathode materials. A number of elements such as $\mathrm{Ti}^{35} \mathrm{Cr}^{36}$ $\mathrm{Mg},{ }^{37,38} \mathrm{~K},{ }^{39} \mathrm{Ru},{ }^{40} \mathrm{Al},{ }^{41} \mathrm{Fe},{ }^{42} \mathrm{Zn},{ }^{43} \mathrm{Si},{ }^{44} \mathrm{Ga},{ }^{45} \mathrm{Mo},{ }^{46,47} \mathrm{Ce},{ }^{48}$ and $\mathrm{F}^{49}$ have been reported for partial substitution of $\mathrm{Ni}, \mathrm{Mn}$, or Co to improve electrochemical performance of the cathode materials. However, to the best of our knowledge, research on the electrochemical performance of electrode-active materials doped by precious metals (Pt, $\mathrm{Au}$, and $\mathrm{Ag}$ ) is seldom reported.

Herein, we focused on substituting $\mathrm{Au}$ for $\mathrm{Mn}$, to explore whether Au doping has any impact on this process. Au is incorporated into $\mathrm{Li}_{1.2} \mathrm{Ni}_{0.7} \mathrm{Co}_{0.1} \mathrm{Mn}_{0.2} \mathrm{O}_{2}$ by a novel approach of electrospinning technology. The effectiveness of Au substitutions on the structure, morphology and electrochemical characterizations of $\mathrm{Li}_{1.2} \mathrm{Ni}_{0.7} \mathrm{Co}_{0.1} \mathrm{Mn}_{0.2} \mathrm{O}_{2}$ was investigated in detail.

\section{Experimental}

\subsection{Materials}

Lithium nitrate $\left(\mathrm{LiNO}_{3}, \mathrm{AR}, 99 \%\right.$, Aladdin Chemistry Co. Ltd., China), nickel nitrate $\left(\mathrm{Ni}\left(\mathrm{NO}_{3}\right)_{2} \cdot 6 \mathrm{H}_{2} \mathrm{O}, \mathrm{AR}, 99 \%\right.$, Aladdin Chemistry Co. Ltd., China), cobalt nitrate $\left(\mathrm{Co}\left(\mathrm{NO}_{3}\right)_{2} \cdot 6 \mathrm{H}_{2} \mathrm{O}, \mathrm{AR}\right.$, 99\%, Aladdin Chemistry Co. Ltd., China), manganese nitrate $\left(\mathrm{Mn}\left(\mathrm{NO}_{3}\right)_{2}, \mathrm{AR}, 50 \%\right.$, Aladdin Chemistry Co. Ltd., China), and gold acid tetrahydrate $\left(\mathrm{AuCl}_{3} \cdot \mathrm{HCl} \cdot 4 \mathrm{H}_{2} \mathrm{O}, \mathrm{AR}, 99 \%\right.$, Aladdin Chemistry Co. Ltd., China) were used as the starting materials. Acetylene black, polyvinylidene fluoride (PVDF) and $N$-methyl-2pyrrolidone (NMP) were bought from Sinopharm Chemical Reagent Co. Ltd. All chemicals were of analytical grade and used without further purification.

\subsection{Preparation of Au-doped $\mathrm{Li}_{1.2} \mathrm{Ni}_{0.7} \mathrm{Co}_{0.1} \mathrm{Mn}_{0.2} \mathrm{O}_{2}$}

$\mathrm{Li}, \mathrm{Ni}, \mathrm{Co}$ and $\mathrm{Mn}$ nitrate salts and Au chlorate were dissolved in dimethylformamide (DMF) and mixed with aqueous solution of polyvinylpyrrolidone (PVP) according to the cationic ratio of $\mathrm{Li}: \mathrm{Ni}: \mathrm{Co}: \mathrm{Mn}: \mathrm{Au}=1.2: 0.7: 0.1: 0.2: X(X=0 \%, 1 \%, 2 \%$, $3 \%$, and $4 \%$ ), which was used to prepare nanofibers. The $\mathrm{Li}_{1.2} \mathrm{Ni}_{0.7} \mathrm{Co}_{0.1} \mathrm{Mn}_{0.2} \mathrm{O}_{2}$ samples doped with different Au content were marked as LNCMA- $X \%$, where $X \%$ represented the atom percent of $\mathrm{AuCl}_{3} \cdot \mathrm{HCl} \cdot 4 \mathrm{H}_{2} \mathrm{O}$. The precursor solution was put into a syringe. A flat piece of aluminum foil was placed about 10-12 cm away from the needle and was used as a fiber collector. A positive direct current (DC) voltage was applied between the needle and the collector to form stable continuous fibers. Then, the pristine fibers were put in a furnace and annealed at $700{ }^{\circ} \mathrm{C}$ for $10 \mathrm{~h}$ with a $2{ }^{\circ} \mathrm{C} \mathrm{min}{ }^{-1}$ heating and $2{ }^{\circ} \mathrm{C} \min ^{-1}$ cooling rate.

\subsection{Characterization methods}

The crystal structure of the as-prepared materials was studied by powder X-ray diffractometry (XRD, Dandong Tongda TD$3000)$ with $\mathrm{Cu} \mathrm{K} \alpha(40 \mathrm{kV}, 30 \mathrm{~mA})$ radiation $(\lambda=1.5406 \AA)$ over the range of $10-90^{\circ}$ at a scanning speed of $0.02^{\circ} \mathrm{s}^{-1}$. The particle morphology and size of the as-prepared products were characterized by a scanning electron microscope (SEM, JMS7610F, JEOL, Japan) and a transmission electron microscope (TEM, FEI Tecnai G2 S-Twin, $200 \mathrm{kV}$ ). Element mapping images obtained using an energy dispersive X-ray spectrometer (EDS, Hitachi S-4800, $10 \mathrm{kV}$ ) were used to clarify the distribution of the element. The surface elemental properties of the selected

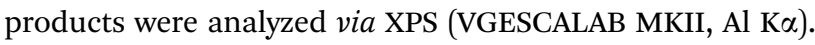

\subsection{Electrochemical measurements}

The electrochemical characterization of the Au-doped $\mathrm{Li}_{1.2}{ }^{-}$ $\mathrm{Ni}_{0.7} \mathrm{Co}_{0.1} \mathrm{Mn}_{0.2} \mathrm{O}_{2}$ was carried out by assembling 2032-type coin cells. The electrode was prepared by mixing active material powders with $10 \mathrm{wt} \%$ super-P carbon black and $10 \mathrm{wt} \%$ polyvinylidene fluoride (PVDF) binder; $N$-methyl pyrrolidone (NMP) was used as solvent. The obtained slurry was uniformly coated onto $\mathrm{Al}$ foil and dried in a vacuum oven at $100{ }^{\circ} \mathrm{C}$ for $24 \mathrm{~h}$. The electrode was pressed and punched into round disks of $15 \mathrm{~mm}$ in diameter. Electrochemical cells consisted of an active material working electrode and a lithium foil counter electrode separated by a Celgard 2400 microporous membrane. The electrolyte solution was $1 \mathrm{~mol} \mathrm{~L}^{-1} \mathrm{LiPF}_{6}$ in a mixture of ethylene carbonate (EC), dimethyl carbonate (DMC) and ethylene methyl carbonate (EMC) in a $1: 1: 1$ volume ratio. The cell assembly was carried out in an Ar-filled glove box with both oxygen and moisture content below 1 ppm. Galvanostatic charge/discharge characteristics of the samples were tested using a battery testing system (NEWARE Co. Ltd., Shenzhen, China) with a voltage window of 2.0-4.8 V vs. $\mathrm{Li} / \mathrm{Li}^{+}$for setting current rates. Electrochemical impedance spectroscopy (EIS) measurements were conducted on an electrochemical workstation (CHI760D, Shanghai Chenhua Co. Ltd). The AC perturbation signal was $5 \mathrm{mV}$ and the frequency range was from $100 \mathrm{kHz}$ to $0.01 \mathrm{~Hz}$. Impedance data analyses were performed using the electrochemical impedance software Zview.

\section{Results and discussion}

\subsection{Structure and morphology characterization of LNCMA-} $\boldsymbol{X} \%$

Fig. 1 shows the XRD patterns of LNCMA- $X \%$. The diffraction peaks for non-doped material were indexed to the hexagonal $\alpha$ -
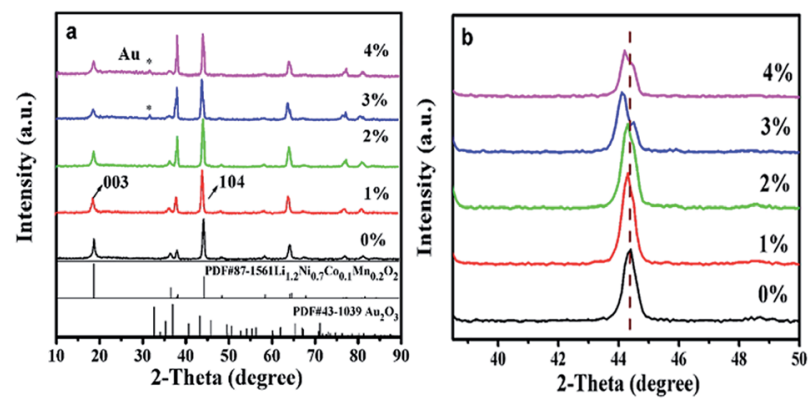

Fig. 1 XRD patterns of the LNCMA-X\% (a) and the magnified patterns of (104) planes (b). 
$\mathrm{NaFeO}_{2}$ layered structure $(R \overline{3} m$ space group). In the doped samples, the main patterns are consistent with the undoped layered structure. However, the gold elemental phase (as marked by asterisks) appears due to the heavy doping amount, providing evidence that Au has been partially inserted into asprepared samples. The crystal structure does not change distinctly with a small amount of Au-doping. Furthermore, with an increase of Au doping level, the main peaks located at about $44^{\circ}$ shift to the lower angle direction as shown in Fig. $1 \mathrm{~b}$. The diffraction peaks of LNCMA- $X \%$ shifted to slightly lower degree due to the larger ion radius of $\mathrm{Au}^{3+}(0.85 \AA)$. The relative intensity of the diffraction peaks strengthened with the increase of Au doping level. In addition, the lattice parameters $\alpha, c, c /$ $\alpha$ and $V$ calculated by using MDI Jade 6.0 software are presented in Table 1 . The lattice parameter $\alpha$ is related to the change in transition metal ionic size. Since the ion radius of $\mathrm{Ni}^{2+}(0.69 \AA)$ and atomic radius of $\mathrm{Au}^{3+}(0.85 \AA)$ are larger than those of $\mathrm{Ni}^{3+}$ $(0.56 \AA)$ and $\mathrm{Mn}^{4+}(0.53 \AA)$, the lattice parameter $\alpha$ increases with an increase in Au doping level. However, the valence of $\mathrm{Ni}$ could partly change from $\mathrm{Ni}^{2+}(0.69 \AA)$ to $\mathrm{Ni}^{3+}(0.56 \AA) .{ }^{50}$ It could result in the slight change of the lattice parameter $\alpha$. The lattice parameter $c$ is related to the transition metal ion radius, lattice strain and cation mixing; it does not increase monotonically with the increase in Au doping level. The lattice parameter $\alpha, c$ and unit cell volumes with the degree of substitutions also in response to the incorporation of the $\mathrm{Au}$ into as-prepared samples. The increase of intensity ratio of $I(003) / I(104)$ indicates that the amount of $\mathrm{Ni}$ in the Li site decreases with $\mathrm{Au}$ doping level less than or equal to $2 \% .^{51,52}$ Since the ionic size of $\mathrm{Ni}^{2+}(0.69 \AA)$ is similar to that of $\mathrm{Li}^{+}(0.76 \AA)$, it is possible that $\mathrm{Li}$ might occupy the transition metal site in addition to the Li site; hence, the degree of cation mixing is increased. However, redundant Li plays a critical role in suppressing cation mixing. It is thought that a great portion of excess $\mathrm{Li}$ is contained in the crystal. This indicates that redundant $\mathrm{Li}$ suppresses $\mathrm{Ni}$ occupation of the $\mathrm{Li}$ site. The results appear to indicate the suppression of phase transformation by controlling the amount of $\mathrm{Ni}$ in the $\mathrm{Li}$ layer. Redundant $\mathrm{Li}$ is primarily thought to occupy the Li site and potentially the surface of cathode. The high $c / \alpha$ value also indicates small cation mixing and good ordering of the transition metal ions in the transition metal layer. It is believed that the enlargement of $c$ and cell volume and the stable hierarchical nanostructure lead to excellent electrochemical properties of LNCMA-2\% (Table 2).

The SEM images of LNCMA- $X \%$ are illustrated in Fig. 2. It can be observed from the low magnification image (Fig. 2a) that the non-substituted nanofibers are rather homogeneous in

Table 1 The lattice parameters of LNCMA-X\%

\begin{tabular}{lllll}
\hline Samples & $\alpha(\AA)$ & $c(\AA)$ & $c / \alpha$ & $V\left(\AA^{3}\right)$ \\
\hline$X=0 \%$ & 2.88609 & 14.1614 & 4.907 & 102.15 \\
$X=1 \%$ & 2.88456 & 14.17844 & 4.915 & 102.22 \\
$X=2 \%$ & 2.88011 & 14.18542 & 4.925 & 102.85 \\
$X=3 \%$ & 2.87354 & 14.24917 & 4.959 & 101.9 \\
$X=4 \%$ & 2.88254 & 14.18702 & 4.921 & 102.09
\end{tabular}

Table 2 Electrochemical impedance parameters of LNCMA-X\%

\begin{tabular}{llrlll}
\hline Sample & $R_{\mathrm{e}}(\Omega)$ & $R_{\mathrm{ct}}(\Omega)$ & $\sigma\left(\Omega \mathrm{s}^{-0.5}\right)$ & $D\left(\mathrm{~cm}^{2} \mathrm{~s}^{-1}\right)$ & $i^{\circ}\left(\mathrm{mA} \mathrm{cm}^{2}\right)$ \\
\hline$X=0 \%$ & 7.62 & 152.53 & 80.73 & $3.99 \times 10^{-13}$ & $1.68 \times 10^{-14}$ \\
$X=1 \%$ & 8.79 & 163.05 & 70.48 & $5.24 \times 10^{-13}$ & $1.58 \times 10^{-14}$ \\
$X=2 \%$ & 5.5 & 97.73 & 40.39 & $1.59 \times 10^{-12}$ & $2.63 \times 10^{-14}$ \\
$X=3 \%$ & 7.1 & 140.17 & 50.98 & $1.00 \times 10^{-12}$ & $1.83 \times 10^{-14}$ \\
$X=4 \%$ & 7.28 & 174.47 & 66.32 & $5.92 \times 10^{-13}$ & $1.47 \times 10^{-14}$ \\
\hline
\end{tabular}

thickness. High magnification photographs (Fig. 2b-f) show that the nanofibers exhibited smooth surfaces with numerous homogenous nano-sized primary particles loosely agglomerated and arranged in the lines, which are supposed to be the nanofibers. Among these oxides, the particle size of LNCMA-2\% is smaller than others. Au doping effectively controls the crystal growth. Such morphology of nanofibers is expected to accelerate electrolyte penetration into the electrode, inhibit the surface reactivity between the electrode and the electrolyte, provide a shortcut for $\mathrm{Li}^{+}$diffusion in the active materials and decrease the dissolution of $\mathrm{Mn}$. Hence, it is expected that the electrochemical performance of LNCMA-2\%, especially rate capabilities, can be enhanced due to Au doping.

Fig. 3 shows the TEM images of the as-prepared LNCMA-2\% products. As shown in Fig. 3a, the sample retains the nanofiber structure with a diameter of $134 \mathrm{~nm}$ after annealing. Moreover, the fiber is composed of nanoparticles with higher crystallization, which is in agreement with the SEM images. The highresolution TEM (HRTEM) image (Fig. 3b) reveals the

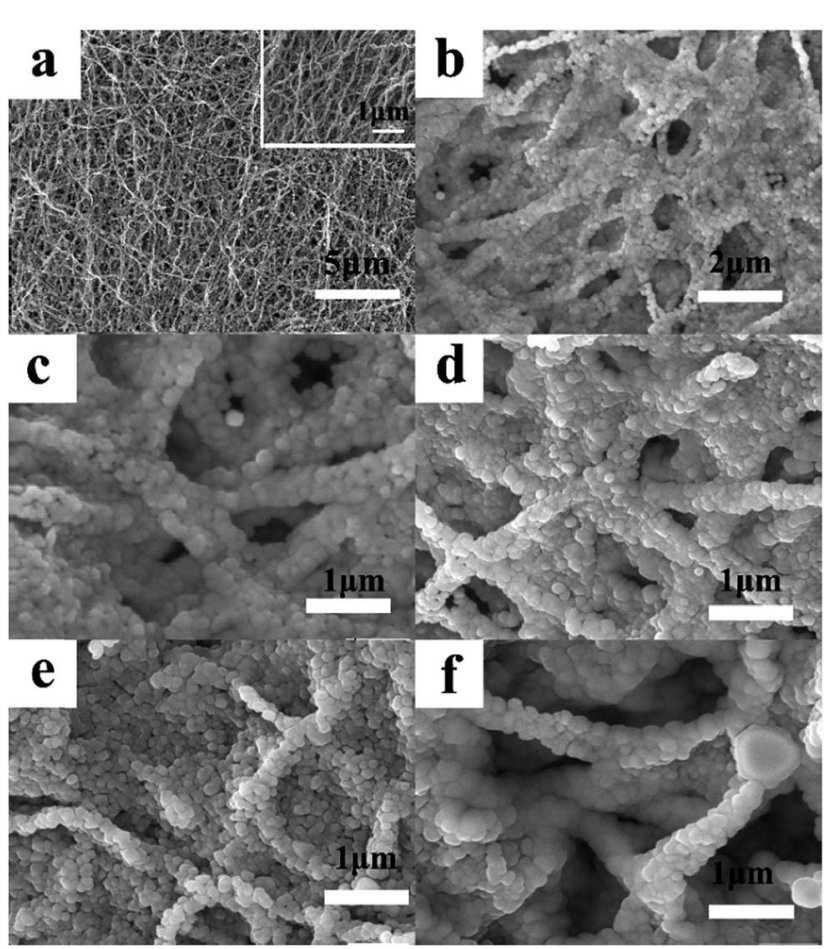

Fig. 2 SEM images of LNCMA-X\% for (a, b) $0 \% A u$, (c) $1 \% A u$, (d) $2 \% A u$, (e) $3 \% \mathrm{Au}$, (f) $4 \% \mathrm{Au}$. 


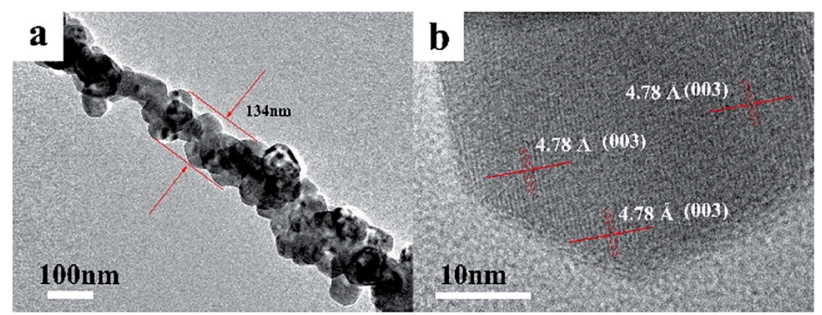

Fig. 3 (a) TEM and (b) HRTEM images of the LNCMA-2\% products.

crystalline features of the nanoparticles. The clear fringes with interplanar spacing of approximately $4.78 \AA$ correspond to the (003) lattice planes of $\mathrm{Li}_{1.2} \mathrm{Ni}_{0.7} \mathrm{Co}_{0.1} \mathrm{Mn}_{0.2} \mathrm{O}_{2}$, consistent with the XRD result (Fig. 1a). In order to confirm the element distribution of LNCMA- $X \%$, the energy dispersive spectrum (EDS) was measured. The EDS images of LNCMA-2\% clearly show the presence of $\mathrm{O}, \mathrm{Ni}, \mathrm{Co}, \mathrm{Mn}$, and $\mathrm{Au}$ in the prepared materials as illustrated in Fig. 4a. In addition, EDS elemental mapping (Fig. 4b-g) confirmed the homogenous and co-existent distribution of $\mathrm{Ni}, \mathrm{Co}, \mathrm{Mn}, \mathrm{O}$, and $\mathrm{Au}$ across the entire nanostructure. Furthermore, the chemical composition and electronic state of elements on the surface of the LNCMA-2\% sample was revealed by X-ray photoelectron spectra (XPS). As shown in Fig. 5, the fitted Ni 2p level shows two peaks at 856.1 and $873.7 \mathrm{eV}$, which can be assigned to $\mathrm{Ni}^{2+} 2 \mathrm{p}_{3 / 2}$ and $2 \mathrm{p}_{1 / 2},{ }^{53}$ respectively. Satellite peaks appear at 860.4 and $879.1 \mathrm{eV}$ due to shake-up processes of $\mathrm{Ni}^{2+} 2 \mathrm{p}_{3 / 2}$ and $\mathrm{Ni}^{2+} 2 \mathrm{p}_{1 / 2}$, respectively. ${ }^{53,54}$ The peaks at 780.0 and $796.4 \mathrm{eV}$ are assigned to $\mathrm{Co}^{2+} 2 \mathrm{p}_{3 / 2}$ and $2 \mathrm{p}_{1 / 2}$, respectively. ${ }^{55,56}$ The peaks at 641.0 and $653.7 \mathrm{eV}$ are assigned to $\mathrm{Mn}^{3+} 2 \mathrm{p}_{3 / 2}$ and $2 \mathrm{p}_{1 / 2}$, respectively, which can be confirmed in the oxidation of air. ${ }^{57,58}$ It can be observed from Fig. 5e that the $\mathrm{Au}^{3+}$ 4f spectrum exhibits the characteristic
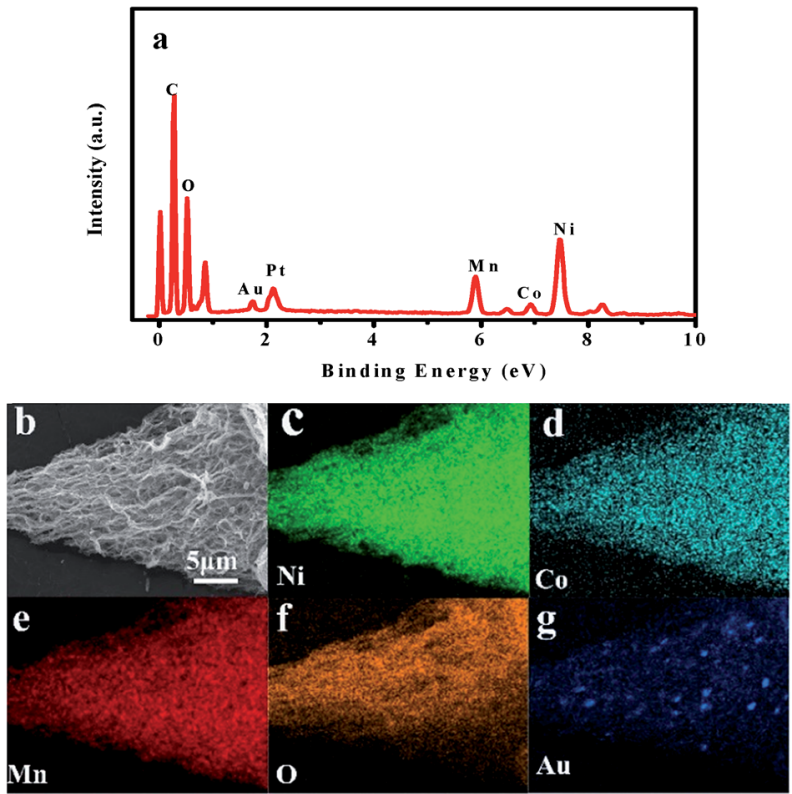

Fig. 4 (a) EDS spectrum, (b) SEM image, and (c-g) EDS elemental mappings of LNCMA- $2 \%$.
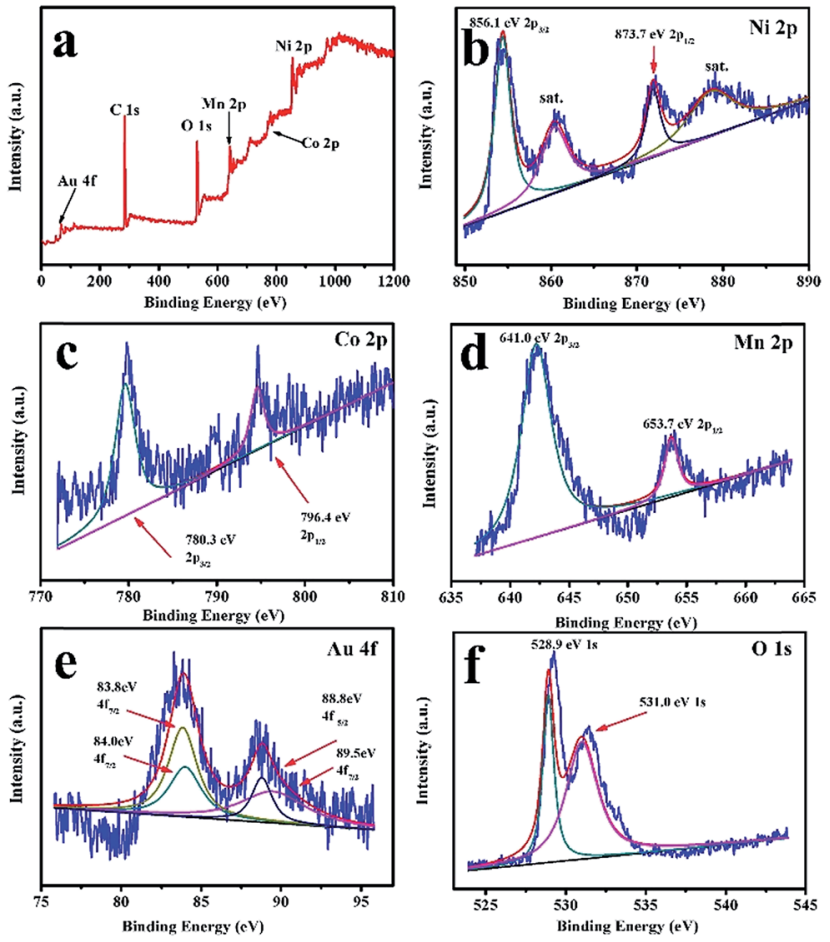

Fig. 5 XPS spectra and corresponding fitting curves of LNCMA-2\% nanofibers. (a) Survey spectrum, (b) Ni 2p, (c) Co 2p, (d) Mn 2p, (e) Au 4f, (f) $\bigcirc 1 \mathrm{~s}$.

peaks at $4 \mathrm{f}_{7 / 2}(83.8 \mathrm{eV})$ and $4 \mathrm{f}_{5 / 2}(89.5 \mathrm{eV})$, and the binding energy at $84.0 \mathrm{eV}$ and $88.8 \mathrm{eV}$ is assigned to the metallic $\mathrm{Au}$ trapped in the LNCMO layer. The different $\mathrm{Au}-\mathrm{O}$ species cannot be distinguished based on XPS spectra from the Au-4f region. ${ }^{59-61}$ This result indicates that $\mathrm{Au}$ is directly bound to $\mathrm{O}$ in LNCMOA. The spectrum of the $\mathrm{O} 1 \mathrm{~s}$ region is depicted in Fig. $5 \mathrm{f}$ and has two peaks at 528.9 and $531.0 \mathrm{eV}$, which correspond to $\mathrm{Ni}-\mathrm{O}$ bond..$^{62-64}$ Clearly, the above analysis indicates the co-existence of $\mathrm{Co}-\mathrm{O}, \mathrm{Ni}-\mathrm{O}, \mathrm{Mn}-\mathrm{O}$, and $\mathrm{Au}-\mathrm{O}$ in this product.

\subsection{Electrochemical performance of LNCMA- $X \%$}

Fig. 6 shows the initial discharge profiles of LNCMA- $X \%$ cathodes. The cells were charged and discharged at a current density of $0.2 \mathrm{C}$. The LNCMA-0\%, LNCMA-1\%, LNCMA- $\%$, LNCMA-3\% and LNCMA-4\% display discharge capacities of 183.243, $179.088,177.441,174.142$ and $168.032 \mathrm{~mA} \mathrm{~h} \mathrm{~g}^{-1}$, respectively. The first discharge capacities of Au-doped samples are lower than that of non-doped material. The discharge capacity of the LNCMA- $4 \%$ is the least. The decrease in discharge capacity in Au-doped samples is attributed to the fact that $\mathrm{Ni}$ in the Li layer disrupts Li diffusion. The voltage decrease is quite smooth before the rapid drop at about $3.7 \mathrm{~V}$. First, since the high valence state is more stable than the low valance state, it may be stable at a high charge state. Second, the ratio of $\mathrm{Ni}^{2+}$ to $\mathrm{Ni}^{3+}$ increases with the Au substitution. Therefore, the Ni valence of Au-doped cathode materials is lower than that of nonsubstituted cathode materials, and this improves 


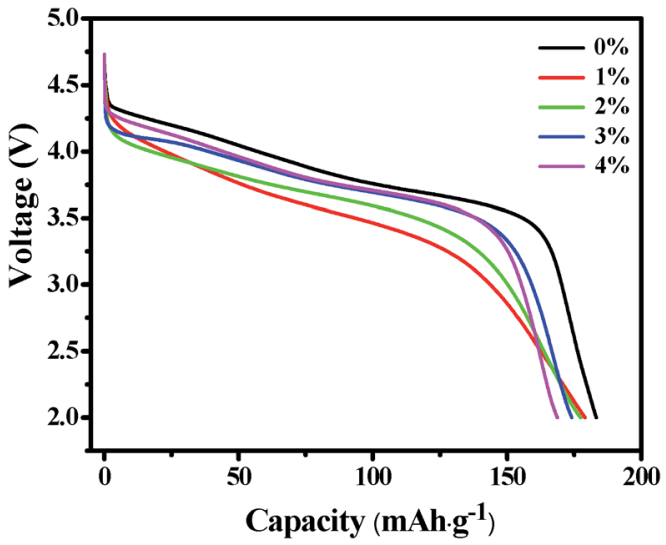

Fig. 6 The initial discharge profiles of the LNCMA-X\% at $0.2 \mathrm{C}$ in the voltage of $2.0-4.8 \mathrm{~V}$

electrochemical stability. The stable structures provide a favorable pathway for fast lithium kinetics. ${ }^{65}$ Moreover, long platforms of discharge curves are associated with electrode stability. Furthermore, an optimized Au amount may suppress the formation of solid electrolyte interface (SEI) film, and the charge transfer resistance may reduce after activation at the beginning of the cycling. This is consistent with the results obtained in the subsequent EIS tests.

Fig. 7 shows the cycle capabilities of LNCMA- $X \%$ electrodes at $0.2 \mathrm{C}$ in the voltage range of $2.0-4.8 \mathrm{~V}$. The capacity retentions after 100 cycles for samples with various levels of Au-doping are $64.2 \%, 67.5 \%, 75.2 \%, 69.1 \%$ and $67 \%$. The impact of the $\mathrm{Au}$ substitution on the cycle capabilities of $\mathrm{Li}_{1.2} \mathrm{Ni}_{0.7} \mathrm{Co}_{0.1} \mathrm{Mn}_{0.2} \mathrm{O}_{2}$ is complicated. Generally, the reversible capacities of Au-doped $\mathrm{Li}_{1.2} \mathrm{Ni}_{0.7} \mathrm{Co}_{0.1} \mathrm{Mn}_{0.2} \mathrm{O}_{2}$ increase at $X$ less than $2 \%$. The excellent cycle capability of Au-doped materials could be attributed to the formation of stronger $\mathrm{Au}-\mathrm{O}$ bonds, which increases the structure stability of the electrode against HF attack. For samples with $X \geq$ $2 \%$, excess Au doping reduces the utilization of active material.

Fig. 8 exhibits the rate capabilities of the LNCMA-X\% cathode. The assembled cells were tested at $0.2 \mathrm{C}$ discharge rate

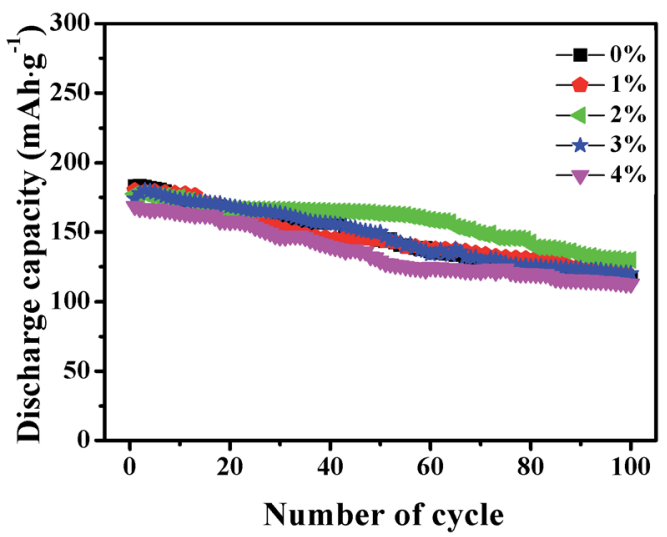

Fig. 7 The cycle capabilities of the LNCMA- $X \%$ at $0.2 \mathrm{C}$ in the voltage range of $2.0-4.8 \mathrm{~V}$. for the first 10 cycles and then at discharge rate from 0.5 to $5 \mathrm{C}$. Again, the LNCMA-2\% displays a better performance and delivers a reversible capacity of $174 \mathrm{~mA} \mathrm{~h} \mathrm{~g}^{-1}$ at discharge rate of $0.2 \mathrm{C}$ after 10 cycles. When the current densities are increased, only a small decrease in capacity is observed. In particular, after LNCMA-2\% undergoes discharge up to 5C, the cathode still delivers a reversible discharge capacity of $96.0 \mathrm{~mA} \mathrm{~h} \mathrm{~g}^{-1}$. A high reversible capacity of $156.4 \mathrm{~mA} \mathrm{~h} \mathrm{~g}^{-1}$ at $0.2 \mathrm{C}$ for LNCMA-2\% can be achieved even at a high discharge rate of $5 \mathrm{C}$ after 50 cycles.

Both the capacity retention decrease and rate capability property suggest that the excess Au doping severely deteriorates the electrochemical performance, which is probably attributed to the formation of a precarious interface structure resulting from the nonequivalent substitution. In addition, the charge transfer becomes slower resulting from the incorporation of highly conductive Au in charge-discharge process, thus leading to excellent electrochemical properties. Therefore, an optimum amount of Au substitution of $2 \%$ in $\mathrm{Li}_{1.2} \mathrm{Ni}_{0.7} \mathrm{Co}_{0.1} \mathrm{Mn}_{0.2} \mathrm{O}_{2}$ could enhance the combination performance of cathodes and excellent discharge capacity and good capacity retention can be obtained.

In order to further explore the impact of Au-doping and investigate the kinetic process of lithium insertion-extraction, the assembled cells were characterized using EIS. As shown in Fig. 9, each of the impedance spectra of LNCMA- $X \%$ electrodes includes three regions. ${ }^{66,67}$ The intercept of the plot with the $\mathrm{Z}^{\prime}$ axis in the high frequency region is ascribed to the electrolyte resistance $\left(R_{\mathrm{e}}\right)$. The semicircle in the medium frequency region reflects the charge transfer resistance $\left(R_{\mathrm{ct}}\right)$ for $\mathrm{Li}^{+}$ion migration through the interface between the surface layer and the electrolyte. ${ }^{68}$

As shown in Fig. 10, the sloping line in the low frequency area is attributed to Warburg impedance $\left(Z_{\mathrm{w}}\right) \cdot{ }^{69}$ The value of $R_{\mathrm{ct}}$ for LNCMA-2\% is $97.73 \Omega$; this electrode displays the lowest charge transfer resistance. The result demonstrates that the $\mathrm{Li}^{+}$ has excellent diffusion performance. It shows that Au-doping has an efficacious effect on restraining the increase in charge transfer impedance of the cathode during cycling. The lower the charge transfer resistance, the higher the electrochemical performance. The small increment in $R_{\mathrm{ct}}$ can be explained as follows: on one hand, the appropriate $\mathrm{Au}$-doping stabilizes the

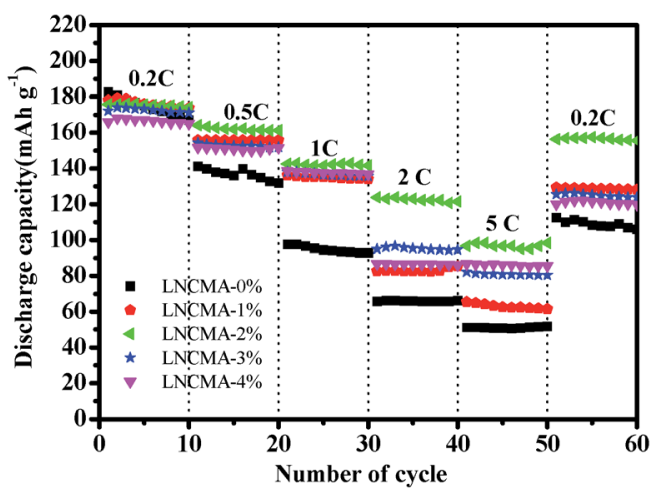

Fig. 8 Rate performance of as-prepared LNCMA- $x \%(x=0,1,2,3,4)$. 




Fig. 9 Impedance spectra of the LNCMA-X\% at open circuit voltage. Inset: equivalent circuit corresponding to the impedance diagrams.

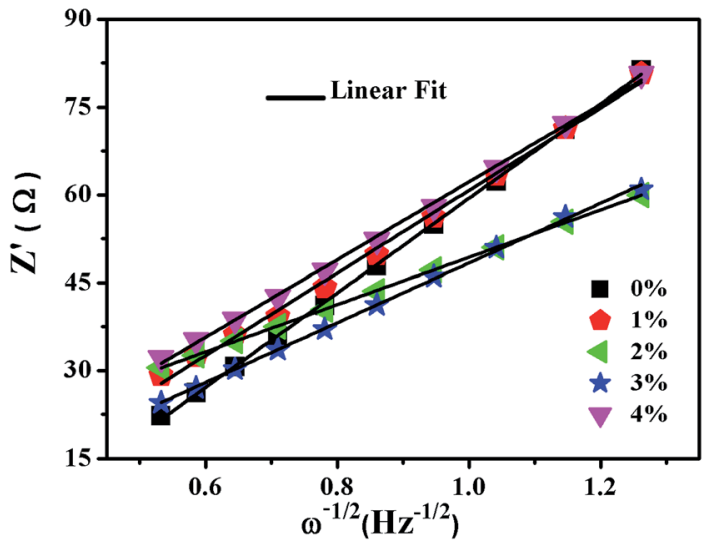

Fig. 10 Fitting line of the $Z^{\prime}$ vs. $\omega^{-1 / 2}$ relationship of LNCMA-X\%.

structure of the sample and suppresses dissolution of metal ions. On the other hand, the formation of better SEI film accelerates Li-ion diffusion from surface layer to the electrolyte. $^{70}$ The EIS results again prove the beneficial effect of $\mathrm{Au}$ modification on layered $\mathrm{Li}_{1.2} \mathrm{Ni}_{0.7} \mathrm{Co}_{0.1} \mathrm{Mn}_{0.2} \mathrm{O}_{2}$.

\section{Conclusions}

The Au-doped $\mathrm{Li}_{1.2} \mathrm{Ni}_{0.7} \mathrm{Co}_{0.1} \mathrm{Mn}_{0.2} \mathrm{O}_{2}(\mathrm{Au}=0 \%, 1 \%, 2 \%, 3 \%$, and $4 \%$ ) cathode materials were successfully prepared by a sample electro-spinning technique. The impact of Au doping on the structure, morphology and electrochemical performances of the resultant products was studied in detail. The optimal amount of Au-doped content is $2 \%$ in $\mathrm{Li}_{1.2} \mathrm{Ni}_{0.7} \mathrm{Co}_{0.1^{-}}$ $\mathrm{Mn}_{0.2} \mathrm{O}_{2}$. The small nanoparticles can flexibly adapt to the volume expansion during the Li-ion insertion/extraction process, which contributes to enhance the structure stability and shorten the diffusion distance of Li-ion. The improvement of electrochemical properties of the LNCMA- $2 \%$ can be attributed to strengthening the surface structure to hinder the dissolution of metal ions and improving the conductivity of the samples. In addition, this improvement can be due to a higher
$\mathrm{Li}^{+}$diffusion coefficient and smaller charge-transfer resistance for the LNCMA-2\%.

\section{Conflicts of interest}

There are no conflicts of interest to declare.

\section{Acknowledgements}

This research has been supported by the Natural Science Foundation of Jilin Province (No. 20170101128JC), the Science and Technology Research Project of the Education Department of Jilin Province during the 13th 5 year plan period (No. 2016359), the Youth Foundation of Changchun University of Science and Technology (No. XQNJJ-2014-13, XJJLG-2014-10), and the Science and Technology Planning Project of Changchun City (No. 2013064).

\section{References}

1 B. Markovsky, A. Rodkin, Y. S. Cohen, O. Palchik, L. Mikhael, D. Aurbach, H. J. Kim and M. Schmidt, J. Power Sources, 2003, 119, 504-510.

2 J. Q. Deng, L. J. Xi, L. H. Wang and Z. M. Wang, J. Power Sources, 2012, 198, 251-257.

3 S. K. Martha, J. Nanda, G. M. Veith and N. J. Dudney, J. Power Sources, 2012, 216, 179-186.

4 H. Zheng, T. Li, X. Song, G. Liu and V. Battaglia, J. Power Sources, 2012, 208, 52-57.

5 S. J. Shi, Y. J. Mai, Y. Y. Tang and C. D. Gu, Electrochim. Acta, 2012, 77, 39-46.

6 P. Manikandan, M. V. Ananth, T. P. Kumar, M. Raju, P. Periasamy and K. Manimaran, J. Power Sources, 2011, 196, 10148-10155.

7 H. M. Wu, J. P. Tu, Y. F. Yuan, J. Y. Xiang, X. T. Chen, X. B. Zhao and G. S. Cao, J. Electroanal. Chem., 2007, 608, 8-14.

8 A. M. A. Hashem, A. E. Abdel-Ghany, A. E. Eid, J. Trottier, K. Zaghib, A. Mauger and C. Julien, J. Power Sources, 2011, 196, 8632-8637.

9 Y. J. Gu, Y. B. Chen, H. Q. Liu, Y. M. Wang, C. L. Wang and H. K. Wu, J. Alloys Compd., 2011, 509, 7915-7921.

10 H. G. Kim, S. T. Myung, J. K. Lee and Y. K. Sun, J. Power Sources, 2011, 196, 6710-6715.

11 G. R. Li, X. Feng, Y. Ding, S. H. Ye and X. P. Gao, Electrochim. Acta, 2012, 78, 308-315.

12 Y. Bentaleb, I. Saadoune, K. Maher, L. Saadi, K. Fujimoto and S. Ito, J. Power Sources, 2010, 195, 1510-1515.

13 Y. W. Lee, J. K. Oh, H. S. Kim, J. K. Lee, S. B. Han, W. ChoiJ and K. W. Park, J. Power Sources, 2010, 195, 5896-5901.

14 X. Zhang, A. Mauger, Q. Lu, H. Groult and L. Perrigaud, Electrochim. Acta, 2010, 55, 6440-6449.

15 Y. Xia and M. Yoshio, J. Power Sources, 1995, 57, 24-28.

16 A. Kraytsberg and Y. Ein-Eli, Adv. Energy Mater., 2012, 2, 922939.

17 B. L. Ellis, K. T. Lee and L. F. Nazar, Chem. Mater., 2010, 22, 691-714. 
18 N. S. Choi, Z. Chen, S. A. Freunberger, X. D. Ji, Y. Sun, K. Amine, G. Yushin and L. F. Nazar, Angew. Chem., 2012, 51, 9994-10024.

19 H. T. Kim, J. S. Park, S. K. Chang, S. D. Choi, J. H. Ryu and H. K. Song, Adv. Energy Mater., 2012, 2, 860-872.

20 J. Xiao, N. A. Chernova and M. S. Whittingham, Chem. Mater., 2010, 22, 1180-1185.

21 S. Muto, K. Tatsumi, Y. Kojima, H. Oka, H. Kondo, K. Horibuchi and Y. Ukyo, J. Power Sources, 2012, 205, 449455.

22 S. Muto, K. Tatsumi, Y. Ukyo, O. Chikaaki, I. Yuichi, K. Yasuhito, T. Yoji, U. Yoshio, T. Kazuyoshi and M. Shunsuke, J. Electrochem. Soc., 2009, 156, A371-A377.

23 Y. Shin and A. Manthiram, ChemInform, 2003, 34, 29542961.

24 V. Aravindan, J. Gnanaraj, Y. S. Lee and S. Madhavi, J. Mater. Chem. A, 2012, 1, 3518-3539.

25 W. Feng, W. Meng, Y. Su and S. Chen, Electrochim. Acta, 2009, 54, 6803-6807.

26 X. Huang, Q. Q. Qiao, Y. Y. Sun, F. Li, Y. L. Wang and S. H. Ye, J. Solid State Electrochem., 2015, 19, 805-812.

27 S. J. Shi, J. P. Tu, Y. J. Mai, M. Y. Zhang, C. D. Gu and X. l. Wang, Electrochim. Acta, 2012, 63, 112-117.

28 Y. J. Kang, J. H. Kim, S. W. Lee and Y. K. Sun, Electrochim. Acta, 2005, 50, 4784-4791.

29 S. H. Lee, B. K. Koo, J. C. Kim and K. M. Kim, J. Power Sources, 2008, 184, 276-283.

30 J. T. Lee, F. M. Wang, C. S. Cheng, C. C. Li and C. H. Lin, Electrochim. Acta, 2010, 55, 4002-4006.

31 J. Zhang, Y. J. Xiang, Y. Yu, S. Q. Xie, G. S. Jiang and C. Chen, J. Power Sources, 2004, 132, 187-194.

32 M. Ménétrier, J. Bains, L. Croguennec, A. Flambard, E. Bekaert, C. Jordy, P. Biensan and D. Claude, J. Solid State Chem., 2008, 181, 3303-3307.

33 W. Feng, W. Meng, Y. Su and S. Chen, J. Power Sources, 2010, 195, 2900-2904.

34 H. Xiang and Z. Peng, Electrochim. Acta, 2011, 56, 7088-7091.

35 A. Mahmoud, I. Saadoune, J. M. Amarilla and R. Hakkou, Electrochim. Acta, 2011, 56, 4081-4086.

36 G. Singh, R. Thomas, A. Kumar and R. S. Katiyar, J. Electrochem. Soc., 2012, 159, A410.

37 D. Wang, Y. Huang, Z. Huo and L. Chen, Electrochim. Acta, 2013, 107, 461-466.

38 W. Luo, F. Zhou, X. Zhao, Z. H. Lu, X. H. Li and J. R. Dahn, Chem. Mater., 2010, 22, 1164-1172.

39 Q. Li, G. Li, C. Fu, D. Luo, J. M. Fan and L. P. Li, ACS Appl. Mater. Interfaces, 2014, 6, 10330.

40 B. Song, M. O. Lai and L. Lu, Electrochim. Acta, 2012, 80, 187195.

41 Y. Weng, S. Xu, G. Huang and C. Jiang, J. Hazard. Mater., 2013, 246-247, 163.

42 K. K. Lee, W. S. Yoon, K. B. Kim, K. Y. Lee and S. T. Hong, J. Power Sources, 2001, 97, 321-325.

43 G. T. K. Fey, J. G. Chen, V. Subramanian and T. Osaka, J. Power Sources, 2002, 112, 384-394.
44 S. H. Na, H. S. Kim and S. I. Moon, Solid State Ionics, 2005, 176, 313-317.

45 J. H. Chang, W. S. Eom, M. L. Sang, W. I. Cho and H. Jang, J. Power Sources, 2005, 144, 214-219.

46 S. H. Park, S. W. Oh and Y. K. Sun, J. Power Sources, 2005, 146, 622-625.

47 L. Q. Wang, L. F. Jiao, H. T. Yuan, J. Guo, M. Zhao, H. X. Li and Y. M. Wang, J. Power Sources, 2006, 162, 1367-1372.

48 R. Vidu, C. Plapcianu and C. Bartha, Ind. Eng. Chem. Res., 2014, 53, 7829-7839.

49 M. Kageyama, D. Li, K. Kobayakawa, Y. Sato and Y. S. Lee, J. Power Sources, 2006, 157, 494-500.

50 H. Konishi, M. Yoshikawa and T. Hirano, J. Power Sources, 2013, 244, 23-28.

51 W. Li, J. N. Reimers and J. R. Dahn, Phys. Rev. B: Condens. Matter Mater. Phys., 1992, 46, 3236-3246.

52 L. Croguennec, I. Saadoune and A. Rougier, Electrochim. Acta, 1999, 45, 243-253.

53 A. N. Mansour, Surf. Sci. Spectra, 1994, 3, 239.

54 A. M. Venezia, R. Bertoncello and G. Deganello, Surf. Interface Anal., 1995, 23, 239.

55 N. S. McIntyre, D. D. Johnston, L. L. Coatsworth, R. D. Davidson and J. R. Brown, Surf. Interface Anal., 1990, 15, 265.

56 C. V. Schenck, J. G. Dillard and J. W. Murray, J. Colloid Interface Sci., 1983, 95, 398.

57 W. H. Chen, Y. Y. Li, J. J. Zhao, F. F. Yang, J. M. Zhang, Q. Z. Shi and L. W. Mi, RSC Adv., 2016, 6, 58173-58181.

58 B. J. Tan, K. J. Klabunde and P. M. A. Sherwood, J. Am. Chem. Soc., 1991, 113, 855.

59 C. Xu, T. Sritharan, S. G. Mhaisalkar, M. Srinivasan and S. Zhang, Appl. Surf. Sci., 2007, 253, 6217-6221.

60 V. D. Putten and R. Zanoni, Phys. Lett. A, 1995, 208, 345.

61 J. J. Pireaux, M. Liehr, P. A. Thiry, J. P. Delrue and R. Caudano, Surf. Sci., 1984, 141, 221.

62 M. S. K. Oku, H. J. M. Tokuda and K. S. K. Hirokawa, J. Electron Spectrosc. Relat. Phenom., 1991, 4, 201-211.

63 E. E. Khawaja, M. A. Salim, M. A. Khan, F. F. Al-Adel, G. D. Khattak and Z. Hussain, J. Non-Cryst. Solids, 1989, 110, 33.

64 A. M. Venezia, R. Bertoncello and G. Deganello, Surf. Interface Anal., 1995, 23, 239.

65 Y. Hu, Y. Zhou, J. Wang and Z. Shao, Mater. Chem. Phys., 2011, 129, 296-300.

66 K. M. Shaju, G. V. S. Rao and B. V. R. Chowdari, Electrochim. Acta, 2004, 49, 1565-1576.

67 K. M. Shaju, G. V. S. Rao and B. V. R. Chowdari, J. Electrochem. Soc., 2004, 151, A1324-A1332.

68 J. Li, C. Cao, X. Xu, Y. Zhu and R. Yao, J. Mater. Chem. A, 2013, 1, 11848-11852.

69 Y. Cho, P. Oh and J. Cho, Nano Lett., 2013, 13, 1145-1152.

70 D. Li, Y. Kato, K. Kobayakawa, H. Noguchi and Y. Sato, J. Power Sources, 2006, 160, 1342-1348. 